\title{
Splitting Process of Sikhote-Alinian Meteorite in the Context of Modern Fracture Mechanics
}

\author{
A.G. Ivanov and V.A. Ryzhanski \\ Russian Federal Nucear Center (VNIIEF), 607190 Sarov, Nizhni Novgorod region, Russia
}

\begin{abstract}
Abatrach. The calculation results of Sikhote-Alinian meteorite interaction with the Earth atmosphere are presented. There are ahown that the process of meteorite fragmentation is divided in space and time into four consecutive steps. It is found that after temination of fragmentation the "pumping" of the largest part of the meteorite energy into a shock wave took place due to intensive deceleration of the meteorite fragments swarm. At certain height the intensity of "pumping" of energy reaches the peak that can cause the effect of the meteocite explosion. The calculation results ane in a good agreement with the actual data.
\end{abstract}

Recume. Le processus de l'interaction entre l'atmosphère terrestre et la météorite Sikhote-Alin a été anslysé. On a montré que le processus de broyage de la météorite était subdivisé en quatré étapes succesaives dans le temps et l'espace. On a constaté que quand le broyage a été teminé la phupart d'energié de la météorite était "pompée" a l'onde de choc à cause de la decélération intensive de l'essaim des fragments de la météorite. A la certaine hauteur l'intensité du pompage d'énergie a atteint son crête et pouvait créer l'effect de l'explosion de la météorite. Les résultats d'estimation concordent d'une manière satiafaisante avec les données réelles.

On February 12, 1947 the bright ball rushed over Primorie (Russia, the Far East) and exploded at height from 5 up to $10 \mathrm{~km}$ above Sikhote-Alinian mountain range. The meteorite fragments falled out with rain in taiga. There were found 24 craters with diameters from 9 up to $26 \mathrm{~m}$ and about 200 funnels and hollows of the smaller sizes [1,2] on the place of their fall. Many fragments were severe destroyed by impact against rocky ground. In taiga there were distributed their numerous small-sized fragments with masses from parts of a gram up to several kilograms (to the middle of the 70's there were picked up more than 3500). Among found intact fragments the largest ones have weights of $1750,1000,700,500,450,350 \mathrm{~kg}$. The total weight of picked meteoric substance was about $27 \mathrm{t}$. Its chemical structure is the following (in percentage of weights): $\mathrm{Fe}-93.29, \mathrm{Ni}-5.94, \mathrm{Co}-0.39, \mathrm{Cu}-0.03, \mathrm{P}-0.56, \mathrm{~S}$ - 0.28. Other elements are contained in insignificant small quantities. The total weight of the metcorite was from $\sim 70$ up to $\sim 100 \mathrm{t}$, velocity of its movement in the atmosphere was $\sim 20$ $\mathrm{km} / \mathrm{s}$.

What are the reason and mechanism of the Sikhote-Alinian meteorite splitting (fragmentation) in the atmosphere?

Some possible mechanisms of interaction between a space solid and the planet atmosphere, as well as the reasons of its fracture are suggested, for example, in [3-5]. For analysis of them we will consider the process of compact dense solid penetration in the Earth atmosphere.

Following [3], we will assume the Earth atmosphere to be isothermal with small thickness of standard atmosphere $(\mathbf{H})$ in comparison with the Earth radius. In this case the dependence of atmosphere density $\rho_{a}$ on the distance to the Earth $z(0 \leq z \leq \infty)$ is expressed by the formula:

$$
\rho_{\mathbf{z}}=\rho_{\mathrm{o}} \exp (-\mathrm{z} / \mathbf{H})
$$


where $\rho_{0}$ is the density of the non-disturbed atmosphere near the Earth surface. For a solid as a ball the dependence of velocity $V$ on $z$, its diameter $D_{0}$, density $\rho_{\mathrm{s}}$, angle of entering the atmosphere $\alpha$, and coefficient of aerodynamic resistance $C_{X}$ is given by the expression:

$$
\mathrm{V}(\mathrm{z})=\mathrm{V}_{\mathrm{o}} \exp \left[-\left(3 \mathrm{C}_{\mathbf{x}} / 4 \sin \alpha\right)\left(\rho_{\mathrm{a}} / \mathrm{\rho}_{\mathrm{z}}\right)\left(\mathbf{H} / \mathrm{D}_{\mathrm{o}}\right) \exp (-\mathrm{z} / \mathrm{H})\right]
$$

It is obtained when solving the differential equation of solid movement in the Earth atmosphere:

$$
\mathrm{dV} / \mathrm{dt}=-\mathrm{C}_{\mathrm{x}}\left(\rho_{\mathrm{o}} / \rho_{\mathrm{B}}\right)\left(\mathrm{V}^{2} / \mathrm{D}\right)
$$

at initial $z=\infty$ and $V=V_{0}$. Pressure in the shock layer of about [3]

$$
p(z) \sim p_{\mathrm{a}} \mathrm{V}^{2}
$$

will define the solid fracture stress $(\sigma)$. We will neglect the solid ablation before its fracture and energy loss due to radiation.

In [3] it is accepted that when achieving the p(z) level appropriate to the critical value $\sigma=\sigma_{*}$ there will be the intensive fragmentation of a solid during $\sim D / C_{S}\left(C_{S}\right.$ is "volumetric" sound velocity in a solid).

In [4] the problem of interaction of a solid with atmosphere is decided much more precisely than in [3]. Local criterion of fracture by action of maximum tangential stresses $\tau_{\max }$ $\geq \sigma_{b}$ ( $\sigma_{b}$ is a breaking limit of a solid at strain) was assumed. The beginning of fracture is associated with the moment, when $\tau_{\max }>\sigma_{b}$ is in some point of a solid. Later on the fracture zone extends and in some moment it takes the whole solid. It is assumed that in this moment the global fracture of a solid takes place.

Thus, according to [3-5], the fracture of a space solid occurs as intensive single fragmentation. The information about the basic sizes of formed fragments is absent.

However, it is known from practice that the solid is destroyed into two approximately equal parts, when load on the solid increases gradually, as it takes place during its penetration into the atmosphere. If keeping the same quasistatic character of the loading, it should be expected that these parts would be destroyed again into two parts, as load increases, etc. These reasons have let us to offer the new basic approach to the analysis of the interaction between a space solid and a planet atmosphere. This approach consists of the following.

For simplification of calculations when clarifying a physical picture of interaction between a space solid and the planet atmosphere it is proposed to:

a) A solid and its fragments have the spherical form.

b) The solid have a diameter $D_{0}$ and consists of a homogeneous material, but it has a sufficient quantity of defects, so after accumulation of necessary elastic energy it is broken in two equal parts.

c) The value of $\sigma_{*}$ is determined by fulfillment of the necessary fracture condition. It implies that a store of elastic energy is equal to the work for breaking it in two parts. Automatic fulfillment of the sufficient fracture condition, namely, existence of defects, is supposed, but in

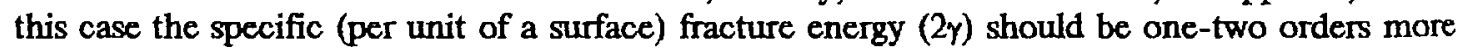
than $2 y$ under static conditions. The similar situation can be realized under intensive dynamic loads as, for example, at spalling [7]. 
d) Following [3], it is assumed that $\sigma \sim \rho_{\mathrm{a}} \mathrm{V}^{2}$, then the elastic energy in a solid with some overestimates will equal to $\sim\left(\rho_{\mathrm{a}}{ }^{2} \mathrm{~V}^{4} / 2 \mathrm{E}\right)\left(\pi \mathrm{D}^{3} / 6\right)$, and fracture work will equal to $\sim 2 \gamma(\pi$ $\left.\mathrm{D}^{2} / 4\right)$.

As the $\sigma_{*}$ value is variable and depends on the object size, within the frames of the taken assumptions it is possible to present the process of the solid fracture when decelerating in the atmosphere to present as a chain of divided in time and space sequential acts of fragmentation into more and more small-sized parts in accordance with increase of aerodynamic resistance. In the end of each stage between the acts of fragmentation, if the necessary fracture condition is fulfilled, the fragments, formed at the previous stage, are again divided in two. The necessary fracture condition at the first stage is the following:

$$
\left(\rho_{\mathrm{a}}{ }^{2} \mathrm{~V}_{1}^{4} / 2 \mathrm{E}\right)\left(\pi \mathrm{D}_{\mathrm{o}}^{3} / 6\right)=2 \gamma\left(\pi \mathrm{D}_{\mathrm{o}}{ }^{2} / 4\right),
$$

whence it follows that

$$
\rho_{\mathrm{a}}^{2} \mathrm{~V}_{1}^{4}=3 \mathrm{~K}_{\mathrm{TC}}^{2} / \mathrm{D}_{\mathrm{O}}
$$

where $\mathrm{K}_{\mathrm{IC}}{ }^{2}=2 \gamma \mathrm{E}$. Volume of the fragment is approximately $\pi \mathrm{D}_{1}{ }^{3} / 6=0,5\left(\pi \mathrm{D}_{0}{ }^{3} / 6\right)$, therefore its size will be approximately $\mathrm{D}_{1}=\mathrm{D}_{\mathrm{o}} / 2^{1 / 3}$. Hereinafter, taking into account the mentioned above, the condition for the fragmentation stage $k(2 \leq k \leq n, n$-number of the last stage) will take the following form:

$$
\rho_{\mathrm{a}}{ }^{2} \mathrm{~V}_{\mathrm{k}}{ }^{4}=3 \mathrm{~K}_{\mathrm{IC}}{ }^{2} / \mathrm{D}_{\mathrm{k}-1}
$$

where the sizes of formed fragments are approximately the following:

$$
\mathrm{D}_{\mathrm{k}}=\mathrm{D}_{\mathrm{o}} / 2^{\mathrm{k} / 3}
$$

and their total number will be $m_{k}=\left(D_{o} / D_{k}\right)^{3}=2^{k}$.

As a meteorite drops, $\rho_{a}(z)$ grows, and $V(z)$ decreases. So, the expression (4) can have the maximum at some $\mathrm{z}=\mathrm{z}_{\max }$ :

$$
\left(\mathrm{z}_{\max }\right)_{\mathrm{k}}=\mathrm{H} \ln \left[\left(3 \mathrm{C}_{\mathrm{x}} / 2 \sin \alpha\right)\left(\rho_{\mathrm{o}} / \rho_{\mathrm{s}}\right)\left(\mathrm{H} / \mathrm{D}_{\mathrm{k}}\right)\right],
$$

whence the condition of $z_{\max }$ absence is followed: $3 C_{X} \rho_{o} H \leq 2 p_{S} D_{k}$ sinc. It is necessary to note that, taking into account (9), $\mathrm{z}_{\max }$ does not depend on V. If the solid saves its size when achieving $z_{\max }$, as it follows from (2), and taking into account (9), its kinetic energy $\left(\sim V^{2}\right)$ decreases in $\boldsymbol{e}$ times. Then fragmentation of it is practically impossible due to the fact that after passing $z_{\max }$ the aerodynamic resistance $\left(\sim \rho_{3} V^{2}\right)$ sharply falls. If condition (6) is not fulfilled on the way to $z_{\max }$, there would not observed any fragmentation during the further movement of the solid. If (6) is fulfilled and there is fragmentation, $z_{\max }$ grows, as $D_{0}$ reduces to $D_{1}, D_{2}, \ldots$, $D_{n}$. Thus, after that the fragmentation process is accompanied by approachement of values $z_{k}$ and $\left(\mathrm{z}_{\max }\right)_{\mathbf{k}}$ up to termination of fragmentation. 
Analysis of the stage-by-stage fragmentation process by integration of (3) with the use of relative coordinates $x_{\mathrm{k}}=\mathrm{z}_{\mathrm{k}} / \mathrm{H}$ results in the formulas for determination of its movement parameters. At the first stage, at initial $\mathrm{V}=\mathrm{V}_{\mathrm{o}}, x=\infty$ :

$$
\begin{aligned}
& \mathrm{V}_{1}=\mathrm{V}_{0} \exp \left[-0,25 \mathrm{~A} \exp \left(-x_{1}\right)\right], \\
& 2 x_{1}+\mathrm{A} \exp \left(-x_{1}\right)+\ln \left(\mathrm{B} / \mathrm{V}_{0}^{4}\right)=0,
\end{aligned}
$$

where $x_{1}=\mathrm{Z}_{1} / \mathrm{H}, \mathrm{A}=\left(3 \mathrm{C}_{\mathrm{X}} \mathrm{H} / 4 \sin \alpha\right)\left(\rho_{\mathrm{o}} / \rho_{\mathrm{T}}\right) / \mathrm{D}_{0}, \mathrm{~B}=12 \mathrm{~K}_{\mathrm{IC}}{ }^{2} /\left(\rho_{\mathrm{o}}{ }^{2} \mathrm{D}_{\mathrm{o}}\right)$. The values of $\mathrm{V}_{1}, x_{1}$ are initial for the second stage, etc. For the stage $\mathrm{k}(\mathrm{k}=2,3, \ldots, \mathrm{n})$ the parameters $\mathrm{V}_{\mathrm{k}}, x_{\mathrm{k}}$ are determined using recurrences:

$$
\begin{gathered}
\mathrm{V}_{\mathrm{k}}=\mathrm{V}_{\mathrm{k}-1} \exp \left(0,25 \mathrm{~A}\left(\mathrm{H} / \mathrm{D}_{\mathrm{o}}\right) 2^{(\mathbf{k}-1) / 3}\left[\exp \left(-x_{\mathrm{k}-1}\right)-\exp \left(-x_{\mathrm{k}}\right)\right]\right\} \\
2 x_{\mathrm{k}}-\mathrm{A} 2^{(\mathrm{k}-1) / 3}\left[\exp \left(-x_{\mathrm{k}-1}\right)-\exp \left(-x_{\mathrm{k}}\right)\right]+\ln \left[\mathrm{B} 2^{(\mathbf{k}-1) / 3} / \mathrm{V}_{\mathrm{k}-1}{ }^{4}\right]=0 .
\end{gathered}
$$

Let us use the above mentioned technique [6] to analyze the process of the SikhoteAlinian meteorite interaction with the Earth atmosphere. Following [4], we will assume a meteorite to be in the form of a ball with weight of $100 \mathrm{t}$, density of substance (iron) $\rho_{8}=7800$ $\mathrm{kg} / \mathrm{m}^{3}, \alpha=40^{\circ}, \mathrm{V}_{\mathrm{o}}=20 \mathrm{~km} / \mathrm{s}$. For a meteorite: $\mathrm{D}_{\mathrm{o}} \approx 3 \mathrm{~m}$, static $\mathrm{K}_{\mathrm{TC}}{ }^{2}=10^{15} \mathrm{~Pa}^{2} \cdot \mathrm{m}[8]$, dynamic- $\sim 10^{17} \mathrm{~Pa}^{2} \cdot \mathrm{m}, \mathrm{C}_{8}=5.9 \mathrm{~km} / \mathrm{s}, \mathrm{C}_{\mathbf{X}}=1$. For the Earth atmosphere: $\mathrm{H}=8000 \mathrm{~m}, \rho_{\mathrm{s}}=1.3$ $\mathrm{kg} / \mathrm{m}^{3}$.

The calculations results at static $\mathrm{K}_{\mathrm{IC}}{ }^{2}$ are given in table, where, except known parameters, $l_{k}=\left(z_{k-1}-z_{k}\right) / \sin \alpha$ and $\tau_{k}=\left(l_{k} / V_{k}\right) /\left(D_{k} / C_{s}\right)$ are the trajectory segments between the acts of the solid fragmentation and appropriate non-dimensional intervals of time, $\delta U_{k}=1$ $-\left(V_{k} / V_{0}\right)^{2}$ is a kinetic energy loss after the stage $k$.

The results of calculations at static $\mathbf{K}_{\mathrm{IC}^{2}}$

\begin{tabular}{|c|c|c|c|c|c|c|c|}
\hline $\mathbf{k}$ & $\begin{array}{c}\mathrm{z}_{\mathbf{k}}, \\
\mathbf{k m}\end{array}$ & $\begin{array}{c}\mathrm{l}_{\mathbf{k}} \\
\mathbf{k m}\end{array}$ & $\tau_{\mathbf{k}}$ & $\begin{array}{c}\mathrm{V}_{\mathbf{k}}, \\
\mathbf{k m} / \mathbf{s}\end{array}$ & $\mathbf{m}_{\mathbf{k}}$ & $\begin{array}{c}\mathrm{D}_{\mathbf{k}} \\
\mathbf{m}\end{array}$ & $\begin{array}{c}\delta \mathrm{U}_{\mathbf{k}} \\
\%\end{array}$ \\
\hline 1 & 15,6 & - & - & 18,60 & 2 & 2,38 & 13,6 \\
\hline 2 & 14,5 & 1,79 & 305,3 & 18,33 & 4 & 1,89 & 16,0 \\
\hline 3 & 13,2 & 2,03 & 445,4 & 17,90 & 8 & 1,50 & 19,9 \\
\hline 4 & 11,5 & 2,57 & 744,9 & 17,10 & 16 & 1,19 & 26,9 \\
\hline
\end{tabular}

The equations (11) and (13) were numerically solved by the combined method accurate to $10^{--6}$. Dependence of a meteorite energy loss $\delta U(z)=1-\left(V / V_{0}\right)^{2}$ and intensities of "pumping" it into a shock wave $\delta U^{\prime}(\mathrm{z})=\mathrm{d}(\delta \mathrm{U}) / \mathrm{dz}$ are indicated in the figure.

It follows from the table and the figure that, as well as in [6], the meteorite interaction with atmosphere is characterized by quasistatic $\left(\tau_{k}>300\right)$ loading of it at the stage A resulted in intensive fourfold fragmentation (on the average, in $l_{k} \approx 2 \mathrm{~km}$ ) at heights from $\sim 16$ up to $\sim 12$ $\mathrm{km}$, and by stage $B$ followed after it, i. e. deceleration of formed fragments swarm. Just at the stage B "pumping" of the largest part of meteorite energy in a shock wave takes place: 


$$
\delta \mathbf{U}_{B}=1-\left(V_{n} / V_{o}\right)^{2} \exp \left\{0,5 A 2^{n / 3}\left[\exp \left(-x_{n}\right)-\exp (-x)\right]\right\} \approx 60 \% .
$$

As this takes place, the intensity of energy "pumping" is in accordance with the dependence:

$$
\delta U_{B}^{\prime}=-0,5\left(V_{n} / V_{0}\right)^{2} A 2^{n / 3} \exp \left\{0,5 A 2^{n / 3}\left[\exp \left(-x_{n}\right)-\exp (-x)\right]\right\} \exp (-x) .
$$

The peak of energy "pumping" intensity, causing the effect of the meteorite "explosion", is reached at the height $H \ln (0,5 A 2 \mathrm{n} / 3) \approx 8 \mathrm{~km}$. It is in a good agreement with the fact, which had a place at the height from 5 up to $10 \mathrm{~km}$. ground is:

Calculated velocity of the meteorite fragments (number of them is 16) impact against the

$$
V_{i}=V_{n} \exp \left\{0,25 \text { A } 2^{n / 3}\left[\exp \left(-x_{n}\right)-1\right]\right\} \approx 6,5 \mathrm{~km} / \mathrm{s}
$$

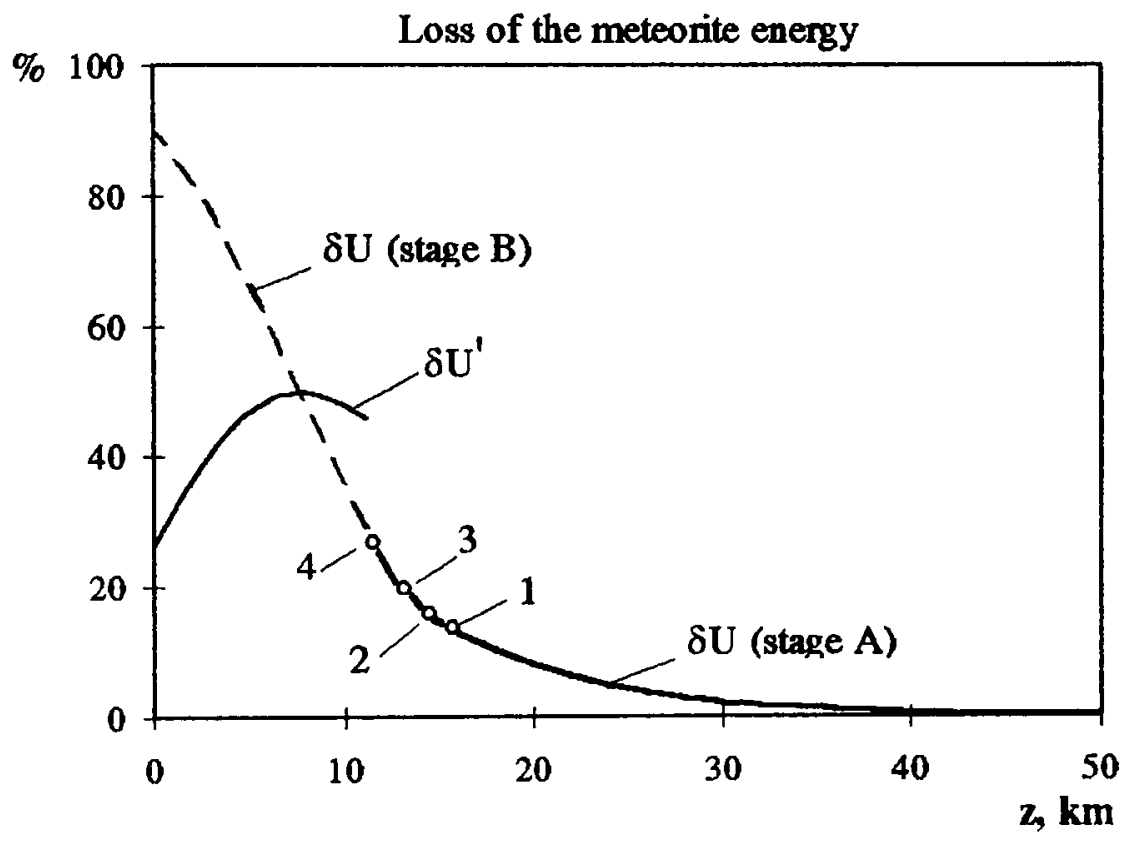

The points $1-4$ - correspond to the acts of the meteorite fragmentation

The energy of a fragment impact is equivalent to explosion of a trinitrotoluene charge with a weight of $\sim 30 \mathrm{t}$. This, according to [9], results in formation of a crater with a diameter of $\sim 36$ $\mathrm{m}$. Also it satisfactorily corresponds to the actual sizes of craters (from 9 up to $26 \mathrm{~m}$ ).

Calculations at dynamic $\mathrm{K}_{\mathrm{IC}}{ }^{2}=10^{17} \mathrm{~Pa}^{2} \cdot \mathrm{m}$ show that the meteorite is intact up to the impact against the ground. Actually it is not so. Consequently, the loading of the meteorite was close to static, and application of dynamic value of $\mathrm{K}_{\mathrm{IC}}{ }^{2}$ is wrong.

Thus, technique [6] lets analyze in details the possible mechanism of the Sikhote-Alinian impact against the Earth atmosphere in the frames of taken assumptions, observe the stages of 
its fracture process, and evaluate basic sizes of fragments, the height of explosion, and the Jiameter crater. Results of the analysis are in a good agreement with the facts. As this takes place, the main result, which differs from [3-5] and is caused by use of integral energetic criterion of fracture, is division of the meteorite fragmentation process in space and time into separate stages. Such a mode of fragmentation let fragments fly away with the help of aerodynamic forces action. This gives us opportunity to consider their fragmentation at the next stage using the same scheme as at the previous stage. However, due to inevitable disorder of physical and mechanical properties of a material in the meteorite volume, actually, the sizes of fragments will be characterized by some dispersion. It is also impossible to exclude that at some stages of the fracture a meteorite or its fragments would be divided not into 2, but into 3 parts. It is natural to expect that the statistical distribution of fragments by sizes will be actually asymmetric with sharp restriction in the field of the large sizes.

As follows from work [2] summarizing the results obtained by 15 expeditions of Committee on Meteorites of USSR Academy of Sciences just in 1947-1978 years, the meteorite disintegration process proceeded in some stages, divided in time and space. It is mentioned in the conclusion of [2] that: "... Study of the morphological characteristics has let us establish trustworthy that the meteoric rain was formed as a result of fragmentation (to say more, repeated fragmentation) the meteoric body, which was unified originally during movement of it with the space velocity in the Earth atmosphere. As a result of research of individual specimens morphological characteristics there were three main stages of fragmentation, proceeded at three different velocities of movement, were formulated..." Comparing the results of [2] and the present work, taking into account the simplifying assumptions when fulfilling calculations, it is possible to testify that used scheme [6] of interactions of a space body with a planet atmosphere reflects more correctly the physical processes than explosive fracture schemes [3-5] and others, and the calculations results are closer to the facts. Moreover, the scheme [6] lets also describe the other attendant effects, such as Shoemakers-Levi comet fragmentation or formation of tectits and the belt of their distribution on the Earth.

\section{REFERENCES}

[1] Sikhote-Alinsky meteoritny dozhd (Coll. art., 1,2, Moskwa, 1959-1963).

[2] Krinov E.L., Zhelezny dozhd (Pub. "Nauka", Moskwa, 1981).

[3] Grigorian S.S., O. dvizhenii i razrushenii meteoritov v atmosferakh planet (In coll. art. "Kosmicheskic issledovania", $\left.17, \mathrm{n}^{\circ} 6,1979\right)$ 875-893.

[4] Korobeinikov V.P., Vlasov V.I., Volkov D.E., Mathematischeskoe modelirovanie, 6, n ${ }^{\circ}$, (1994) 6175.

[5] Fadeenko Ju.I., Fizika gorenia i vzryva, $n^{\circ} 2$ (1967) 278-280.

[6] Ivanov A.G., Ryzhansky V.A., Fizika gorenia i vzryva, nº (1995) 117-124 (correct. in Fizika gorenia i vzryva, $n^{\circ} 3,1996$ )

[7] Ivanov A.G., Prikladnaia mechanika i technicheskaia fizika, $n^{\circ} 3$ (1194) 116-131.

[8] Wicks U.F., Assur A., (In coll. art. "Razrushehie",7, part I, Pub. "Mir", Moskwa, 1976) 513-623.

[9] Ivanov B.A., (In coll. art. "Mechanika. Novoe v zarubezhnoi nauke", series 26 "Udar, vzryv 1 razrushehie". Pub "Mir", Moskwa, 1981) p.231. 